\title{
Analysis of Bending Bearing Capacity of Fully Bolted Outer Shell Beam-Column Joint Connected by T-Stub
}

\author{
Dan Zhang ${ }^{1, a}$, Lei Zhang ${ }^{1, b}$ \\ ${ }^{1}$ School of Civil Engineering, Hunan City University, Yiyang, China \\ a601041777@qq.com, ${ }^{b}$ 625338950@qq.com
}

Keywords: beam-column joint; outer shell; T-stub; bending bearing capacity

Abstract. In the analysis of steel frame, the bearing capacity of joints is the basic mechanical property. With reference to the component method proposed in the Eurocode 3 (EC3) specification, based on the characteristic of transmitting force in each component of the outer shell joints, the bearing capacity of T-stub connection is controlled by the component with the smallest bearing capacity. The calculation method and flow of the bearing capacity of the outer shell joints were put forward, and compared with the experimentally obtained bending moments. This method is in line with engineering design, and is easy to be applied in practice.

\section{Introduction}

Beam-column joints are important parts of steel frame structures. Different connection forms have significant influences on the seismic performance of a structure [1]. In the 70s-80s, the United States, Japan, and other countries tested a large number of joints, and welded joints became the main form of beam-column connection in steel frames. However, the Northridge and Kobe earthquakes showed that these beam-column welded joints did not form plastic hinges on the beam to dissipate earthquake energy as expected, instead of a great degree of brittle fracture [2,3]. The traditional steel frame beam-column joints did not withstand the earthquake test. This raised concerns among civil engineers.

In order to avoid the adverse effects of heat-affected zones because of welding, improve the seismic performance of traditional joints, as well as speed up the assembly, the outer shell joint of rectangular tubular columns and $\mathrm{H}$-stub beams, which is connected by T-stub and high strength bolts, is proposed, as shown in Figure 1.

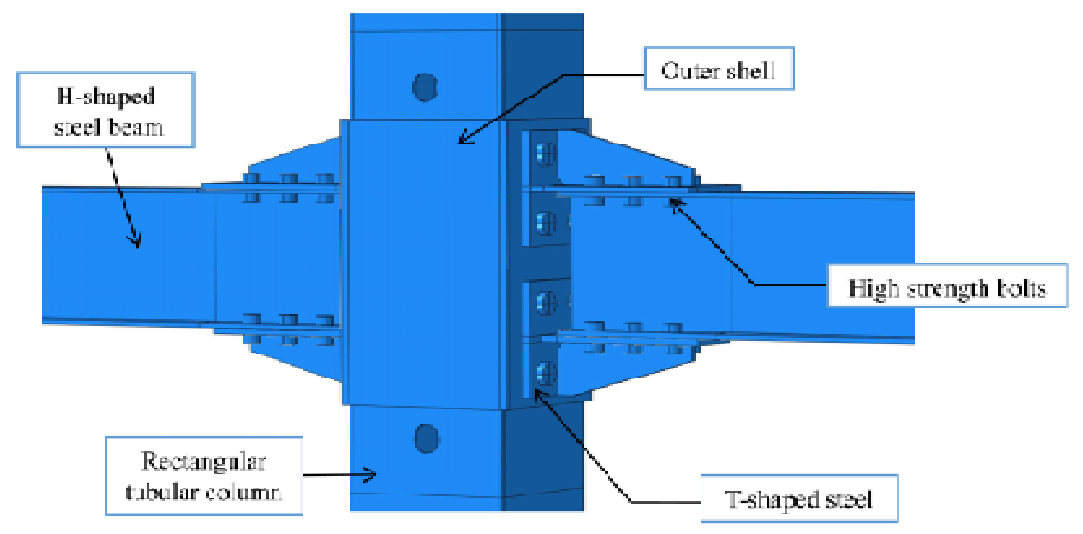

Figure 1. Schematic diagram of outer-shell joint

At present, there have been a lot of research results on rectangular tubular column and $\mathrm{H}$-shaped beam, however, few tests were conducted as a new type of outer shell joint [4]. And the existing studies were not comprehensive. Hence, further theoretical analysis is required. In this study, the calculation method of ultimate bearing capacity was proposed, and its result was compared with existing test results [5]. These results can be applied to the structural analysis of the overall, providing references for the structure design. 


\section{Calculation of bearing capacity}

Under the action of vertical load on the beam end, the bending moment can be transformed into the horizontal force couple $F_{t, j}$ acting on the upper and lower flanges of the beam, if the bending capacity of the beam web was assumed to be ignored. On the basis of the force transferring path of components, the possible failure modes of the node area as follows: (1) bending damage of the beam end, (2) shear failure of high strength bolts on the beam flange, (3) tensile failure of T-stub web, (4) local tensile failure of the T-stub flange, (5) bolts failure between the T-stub flange and the column wall under the combined action of shear and tension, (6) local tensile failure of the column flange, and (7) shear failure of the steel tubular column web in the core region of the joint.

Bearing capacity of joint. The joint includes the beam flange and high-strength bolts, the T-stub web, the T-stub flange, and the column wall, in which the minimum tensile strength $F_{t, j}$ is considered as the bearing capacity.

Bearing capacity of beam flange. According to material mechanics, the yield bearing capacity of the beam flange $F_{t, b}$ can be expressed as Equation 1:

$$
F_{t, b}=f_{y}\left(b_{f}-n_{b} d\right) t_{f}
$$

Where $f_{y}$ is the yield strength of the beam flange, $b_{f}$ is the width of the beam flange, $n_{b}$ is the number of high strength bolts of the beam flange section, $d$ is the diameter of the high strength bolt, and $t_{f}$ is the thickness of the beam flange.

Bearing capacity of sliding surface between the $T$-stub web and the beam flange. After pre-tension was applied to the bolts according to the design value, the loads were transferred between the two components based on friction, and the bearing capacity was calculated using Equation 3 of GB50017-2003 [6]:

$$
F_{t, b f}=0.9 n_{f} \mu P \times n_{b}
$$

Where $n_{f}$ is the number of friction surfaces, $\mu$ is the anti-sliding coefficient of the friction surface, $P$ is the pre-tension of each high strength bolt.

Bearing capacity of high strength bolts. 1) Bearing capacity of high strength bolts in beam flange:

$$
F_{t, b c}=n_{v} \frac{\pi d^{2}}{4} f_{v}^{b} \times n_{b}
$$

Where $n_{v}$ is the number of shear surfaces, $f_{v}^{b}$ is the design value of the shear strength of bolts.

2) Bearing capacity of high strength bolts in column flange: The high-strength bolts of the column wall were subjected to shear force between the friction surfaces and the tensile force in the bolt axis direction. According to the provisions of the Code for Design of Steel Structure[6], bearing capacity can be derived as the following:

$$
F_{t, b t}=0.8 n_{c} P \times\left(1-\frac{V}{0.9 m^{\prime} n_{f} \mu P}\right)
$$

Where $V$ is the vertical shear force at the beam end, $m$ ' is the total number of high strength bolts on the column flange, and $n_{c}$ is the high-strength bolt numbers of the column flange of the tensile zone. The meaning of other parameters are the same as mentioned previously.

Bearing capacity of T-shaped web. The bearing capacity of the T-shaped web is controlled by the cross-section weakened by the bolt holes. Assuming that the beam web and the stiffening rib of the T-section steel bear all shear force, the tensile capacity of the T-shaped web is only considered, as shown in Equation 5:

$$
F_{t, t w}=\left(b_{t w}-n_{t} d\right) t_{t w} f_{y, t w}
$$

Where $b_{t w}$ is the width of the T-stub web, $n_{t}$ is the number of high-strength bolts on the T-shaped web section, $d$ is the diameter of the bolt hole, $t_{t w}$ is the thickness of the T-shaped web, and $f_{y, t w}$ is the 
yield strength of the T-shaped web.

Bearing capacity of T-stub flange. The beneficial influence of stiffening ribs on the tensile strength of the T-stub flange was ignored. Based on the tensile bearing capacity analysis of the T-shaped flange, three failure modes of the T-stub flange were observed: tensile yield, simultaneous damage of the T-shaped flange and bolts, and tensile failure of high-strength bolts [7]. The failure modes were mainly determined by the relative strength of the T-shaped flange and tensile bolts. The bearing capacity of the T-shaped flange $F_{t, t f}$ was determined by the minimum values $F_{1}, F_{2}$, and $F_{3}$ of the above three failure modes, and it was calculated according to Equation 6:

$$
F_{t, f f}=\left\{F_{1}, F_{2}, F_{3}\right\}_{\min }=\left\{\frac{4 \mathrm{M}_{p 1}}{m}, \frac{2 \mathrm{M}_{p 2}+n \sum F_{b o}}{m+n}, 0.8 P \times n\right\}
$$

Where $M_{p 1}$ is the resistance moment when the T-shaped flange yielded, $M_{p 2}$ is the resistance moment when the T-shaped flange and bolts yielded at the same time, $\sum F_{b o}$ is the total tensile capacity of the four tension bolts on the T-shaped flange, $\sum F_{b o}=4 \times 0.8 P, m$ is the distance between the center of the bolt hole and the plastic hinge formed at the T-shaped flange, and $n$ is the distance from the bolt hole center to the edge of T-shaped flange.

Local tensile bearing capacity of the column flange. According to the local tensile plastic hinge line model of the column flange, on the condition of cooperative work between the outer shell and the column flange, the plastic bending moment on the plastic hinge line of the unit length is $M_{p}=f_{y}\left(t_{c f}+t_{b}\right)^{2} / 4$, where $t_{c f}$ is the thickness of the column flange, $t_{b}$ is the thickness of the outer shell, and $f_{y}$ is the yield strength of the column [8]. Then, the local tensile bearing capacity of the column flange $F_{t, c y}$ is calculated by Equation 7:

$$
F_{t, c f}=4 \times M_{p}\left(\frac{2 Y+W}{X}+\frac{2 X+H}{Y}\right)
$$

Where $W$ is the horizontal spacing of bolts, $X$ is the vertical distance from the outside horizontal yield line to the nearest bolt hole, $Y$ is the horizontal distance from the outside vertical yield line to the bolt hole, and $H$ is the vertical spacing of bolts.

After the bearing strength of each component was determined, the bearing capacity of the joint $F_{t, y}$ was controlled by the minimum value, as shown in Equation 8:

$$
F_{t, j}=\min \left\{\begin{array}{l}
F_{t, b}=f_{y}\left(b_{f}-n_{b} d\right) t_{f} \\
F_{t, b f}=0.9 n_{f} \mu P \times n_{b} \\
F_{t, b c}=n_{v} \frac{\pi d^{2}}{4} f_{v}^{b} \times n_{b} \\
F_{t, b t}=0.8 n P \times\left(1-\frac{V}{0.9 m^{\prime} n_{f} \mu P}\right) \\
F_{t, t w}=\left(b_{t w}-m d\right) t_{t w} f_{y, t w} \\
F_{t, t f}=\left(F_{1}, F_{2}, F_{3}\right)_{\min } \\
F_{t, c f}=4 \times M_{p}\left(\frac{2 Y+W}{X}+\frac{2 X+H}{Y}\right)
\end{array}\right.
$$

Bearing capacity of outer shell joint. The bearing capacity takes the minimum value of the bearing capacity of all components. So the calculation of the bending capacity of the outer-shell joint is calculated by Equation 9:

$$
M_{j}=F_{t, j}\left(h_{b}+t_{w}\right)
$$

Where $F_{t, j}$ is the bearing capacity of the joint, $h_{b}$ and $t_{w}$ are the section height of the beam and thickness of the T-shaped web, respectively. 
Calculation of shear strength of joint area. According to the symmetry of the joints, the right side was considered for analysis, and the internal force analysis diagram is shown in Figure 2. The horizontal shear force of the steel tube column $V_{j}$ was calculated using Equation 10:

$$
V_{j}=2 F_{t, v}-F_{t, v}\left(h_{b}+t_{c w}\right) / H
$$

Where $F_{t, v}$ is the horizontal load of the beam flange, $h_{b}$ is the beam section height, and $H$ is the distance from the inflection point of the column to the beam flange.

When the web of the steel tube column in the joint area yield, the shear force $V_{y}$ is calculated using Equation 11 [9]:

$$
V_{y}=A_{c w} \tau_{y}
$$

When $A_{c w}$ is the sectional area of the steel tube column web and $\tau_{y}$ is the shear stress of the steel tube web at yielding.

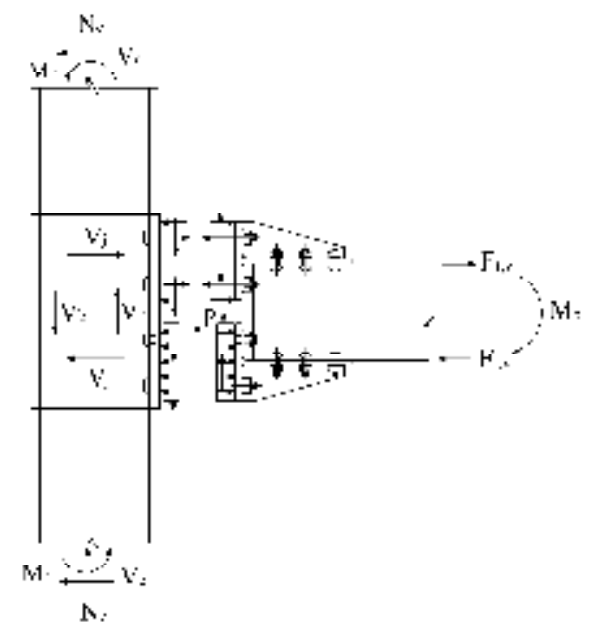

Figure 2. Internal force analysis diagram of joint area.

We take the steel tubular joint as an example and let the horizontal shear force in the joint area $V_{j}$ be equal to the yield shear force of the steel tube column web $V_{y}$. Then, the horizontal load of beam flange $F_{t, v}$ is:

$$
F_{t, v}=\frac{A_{c w} H \sqrt{f_{y}^{2}-\sigma_{w}^{2}}}{\sqrt{3}\left(2 H-h_{b}-t_{c w}\right)}
$$

If the shear capacity of the steel tubular joints is higher than the bending capacity, that is, $F_{t, v}>F_{t, j}$, then the bending failure occurs first. Therefore, the bearing capacity of the joint is in accordance with the seismic design requirements of "strong shear and weak bending" and vice versa.

Comparison between theoretical and experimental values of bearing capacity.The bearing capacity $M_{j, u}$ is calculated according to the above calculation process and compared with the test results $M_{j, e}[5]$ of two group specimens, as shown in Table 1.

Table 1. Comparison between theoretical calculations and experimental values.

\begin{tabular}{cccccccccccc}
\hline $\begin{array}{c}\text { Bearing } \\
\text { capacity }\end{array}$ & \multicolumn{1}{c}{$F_{t, j}[\mathrm{kN}]$} & & & & $\begin{array}{c}\text { Calculate } \\
M_{j, u} \\
{[\mathrm{kN} \cdot \mathrm{m}]}\end{array}$ & $\begin{array}{c}\text { Experimental } \\
M_{j, e} \\
{[\mathrm{kN} \cdot \mathrm{m}]}\end{array}$ & $\begin{array}{c}M_{j, u} / \\
M_{j, e}\end{array}$ \\
\hline \multirow{2}{*}{ Group A } & 313 & 270 & 374 & 385 & 422 & 446 & 512 & 473.2 & 129.6 & 156 & 0.83 \\
Group B & 481 & 665 & 841 & 570 & 568 & 631 & 908 & 715.7 & 275.83 & 245 & 1.12 \\
\hline
\end{tabular}

It is seen from Table 1 that in group A, the bearing capacity is controlled by the friction $F_{t, b f}$ between the high-strength bolts and the beam flange. However, after the friction between the 
connecting plates is overcome, the bolts and plates continue to bear the load. Based on the calculated result, the failure mode of the joint was ultimately controlled by the tensile strength of the beam flange $F_{t, b}$, and the shear strength of the joint area satisfied the design requirements of "strong shear and weak bend",that is, $F_{t, v}>F_{t, j}$. In Group B, the smallest ultimate tensile strength is the beam flange $F_{t, b}$, which was only second to the tensile strength of the T-stub web $F_{t, t w}$, and the horizontal shear strength also satisfied $F_{t, v}>F_{t, j}$.

The ratio of the calculated and experimental values of each group was 0.83 and 1.12 respectively, indicating good agreement. The results of group A were lower than the experimental values, illustrating that the theoretical calculation results are reliable. For group B, brittle fracture occurred in the T-stub web when the plasticity of the beam flange was not fully developed. However, the bearing capacity values of the theoretical and experimental results were still relatively close. Therefore, under the premise of guaranteeing the processing quality, the mastery of the basic information on the specimen can be used to make a preliminary judgment on the failure mode and bearing capacity of the joint.

\section{Conclusions}

The bending bearing capacity of fully bolted outer shell joint connected by T-stub is influenced by different components. It is necessary to comprehensively analyze the stress conditions of each component, so as to obtain a more realistic bending moment of joint. The calculation method and procedure of bearing capacity of the outer shell joints were proposed. The theoretical calculated ultimate bending moments were compared with test results, indicating good agreement. Under the premise of guaranteeing the processing quality, the bearing capacity of joints can be judged if the basic information of the specimens can be mastered.

\section{References}

[1] Kishi N and Chen W.F. Moment-rotation relations of semirigid connections with angles[J]. Journal of Structural Engineering,116(7): 1813-1834.

[2] Papazoglou A.J. and Elnashai A.S. Analytical and field evidence of the damaging effect of vertical earthquake ground motion [J]. Earthquake Engineering and Structural Dynamics, 25(10): 1109-1137.

[3] Nakashima M and Chusilp P. A partial view of Japanese post-Kobe seismic design and construction practices $[\mathrm{J}]$. Earthquake Engineering and Engineering Seismology, 4(1): 3-13.

[4] Li L.M. Study on outer-shell beam-column connection and its application in frame-concrete tube structures [D]. Ph.D. thesis, Tongji University, Shanghai, ON, China.

[5] Zhang D, Tao Z, Zhang L. Experimental and Numerical Analysis of the Seismic Behavior of Outer Shell Joints for H-Shaped Steel Beam and Square Tubular Column[J]. Journal of Engineering Science and Technology Review, 10 (2):178-190.

[6] GB50017-2003. Code for Design of Steel Structure. China Planning Press.

[7] Chasten C.P., Lu L.W. and Driscoll G.C. Prying and shear in end-plate connection design[J]. Journal of Structural Engineering, 118(5): 1295-1311.

[8] Tagawa $\mathrm{H}$ and Gurel S. Application of steel channels as stiffeners in bolted moment connections[J]. Journal of Constructional Steel Research, 61(12): 1650-1671.

[9] He YB, Li Y, Cao HX, et al. Experimental research on and calculation method for the shear strength of composite column-to-beam connections through T-stubs[J]. Journal of Hunan University (Natural Sciences), 39(11):1-6. 